\title{
Sirmilik, Geographical ExPERIENCE, AND THE QUESTION OF LANDSCAPE
}

\begin{abstract}
Traditional landscape aesthetics, featured in geography and the fine arts, privilege a form of distance firmly attached to the gaze of the European colonial. This conceptualization of space has been strongly criticized and has recently been overshadowed in academia by an emphasis on a multisensory form of embodied experience. In contrast to this shift of emphasis, Martin Heidegger placed traditional structures of contemplation alongside an embodied process when accounting for our relationship to landscape and space. Zacharias Kunuk emphasizes this problematization from the indigenous point of view in his latest short film, Sirmilik (2011). In the film he challenges the notion that one form of experience can be separated from the other when considering the arctic landscape.

Key words

Zacharias Kunuk; Canadian National Parks Project; cultural geography; landscape aesthetics; phenomenology
\end{abstract}

The European discourse surrounding landscape aesthetics and the role of film technology began along the same trajectory, one that veered away from imitation and towards realism. Both were profoundly modern phenomenon which relied on their tropes of naturalism and transparency in order to validate their new modes of visual perception (Mitchell 2002: 13). The concept of landscape operates necessarily out of its own entrenched origin myth which constructs a break with previous depictions of nature. This aesthetic of naturalization, which attempted to close the gap between representation and nature, is closely related to earlier political, economic and scientific developments beginning in the $15^{\text {th }}$ century, many of which would go on to use landscape art as a screen to mask certain ideologies 
at the heart of colonialism (Mitchell 2002). In the past few decades there has been a revival of interest in the landscape concept within various disciplines including geography and film studies. Geography has had what some academics have called a "humanist renaissance", engaging with other disciplines through a textual or phenomenological approach to landscape representations (Cosgrove 1985: 45). This shift has brought along a new set of concerns about the philosophical relevancy of the term and the historical baggage which comes along with it.

Two thousand and eleven marked the centennial anniversary of the creation of the Canadian National Park system and was commemorated through the creation of a series of artistic projects, including thirteen short films. One of these filmmakers took the opportunity to engage with the dynamic ideological and historical forces at play in landscape aesthetics. In Zacharias Kunuk's Sirmilik the concept of landscape is politicized through a complex juxtaposition of traditional aesthetic compositions and embodied views. The transition between different forms of visual distance and detachment emphasizes the role of geographical knowledge (and its representation) in maintaining specific power structures in the Canadian North. Like all of Kunuk's other films, Sirmilik participates in a larger postcolonial discourse, but, unlike many of the others, it does so by drawing on the tropes embedded in the history of landscape aesthetics in order to destabilize the internal epistemological narrative constructed therein.

This article engages with both sides of the landscape narrative that are depicted in Sirmilik and attempts to reconcile the tension between them by examining the way they interact through Heidegger's reconceptualization of the notion of dwelling. It begins by examining the role of traditional landscape aesthetics in the colonial imagination and then turns back to Kunuk's film which situates the two within the discourse of scientific objectivity and geographic knowledge. While the article will examine facets of landscape's cultural lineage, it is not interested in repeating ground that has already been explored repeatedly by other academics. I am more concerned with the theoretical debate over the nature and mediation of space and place represented in Sirmilik and the underlying epistemological assumptions which are realized in different forms and framing of landscape.

The arctic landscape has always had a privileged place inside Kunuk's work. He has explored many different themes revolving around the Canadian Inuit and the relationship they have to their ancestral homes inside such films as Exile (2009), Kiviaq vs. Canada (2006), and the television series Nunavut: Our Land (1995). His most well-known work, The Fast Runner Trilogy (2001-2008), formed an allegory of colonization, depicting a time before, during, and after contact with Europeans. It takes place in and around Igloolik and uses a cast of community members who perform the roles of their ancestors. The formal choices made by Kunuk in the trilogy construct a place very much at odds with traditional definitions of landscape; the land depicted is no longer the site of detached aesthetic contemplation but one that we as viewers are pulled into and engage with through the lives of the characters. His formal style and narrative tie images of the land to the gaze and movement of the individual characters; there are very few 
shots composed just of landscape and those that do are sutured into the narrative through carefully composed eye line matches. In this case, Kunuk wrestles with film's relationship to other artistic media by presenting a landscape which exists in a certain temporality, one which follows the rhythms of life for the Inuit.

Sirmilik marks a stylistic departure for the filmmaker. The ten minute piece is mostly made up of images without individuals, focusing instead on different, often contradictory, ways of framing and moving through the Sirmilik National Park in Nunavut. Out of a total of sixty eight shots, eighteen depict the individuals who live there. The other fifty roughly fit into the following categories: aerial views, static long shots, slow panoramas, time lapse photography and tracking shots which move along the ground. This article will explore the conceptual history of these formal approaches to landscape and the relationship they have with the people depicted in the film. It will compare traditional forms of representation from geography and aesthetics, which value contemplation and distance, with expressions firmly inserted inside embodied experiences. All of Kunuk's films play with identity, meaning and place. His National Parks Project is able to go even further because of its antagonistic construction of a historically politicized space.

Landscape representations traditionally function as stand-ins for experiences and knowledge of the natural world. The double layered meaning which they express conflates the act of viewing with the act of representation. In W.J.T. Mitchell's influential essay Imperial Landscape, the term landscape is described as "already artifice in the moment of its beholding" (2002: 14). The subject matter always exists as its own encoded, symbolic form prior to being painted. It exists as a piece of the cultural imaginary even before the artist steps outside his door. The construction of the quest for the pure experience of landscape, one "seen for its own sake", is organized around the emancipation of representation from literary associations and previous conventions (Mitchell 2002: 12). The modern world had "evolved" away from imitation, towards naturalization and finally a unified, objective duplication of the real, one that engaged directly with the aspirations of scientific rationalism. This teleology concealed the layers of complex cultural meaning embedded inside the image, a "double semiotic structure" which both "articulated" and "disarticulated" its own artifice (Mitchell 2002: 17). Any discussion about the landscape idea has to come to terms with the duality that the term implies.

The illusion of transparency masked an entire set of aesthetic conventions and ideology which had come to the fore in Western Europe at the beginning of the $17^{\text {th }}$ century. Imperialism utilized the same tropes as landscape to naturalize its ideology of global expansion. Mitchell argues that the landscape idea is a symptom of the rise and development of capitalism. He uses Marx's conception of the social hieroglyph to describe how landscape functions as "emblem of the social relations it conceals" (2002: 15). Landscape painting embraces the idyllic, the beautiful and the sublime by eliminating any signs of those individuals who originally lived there. European landscape conventions, like the picturesque, were transported across the globe alongside colonialism. Foreign landscapes were 
transformed by the European gaze and imagination to become a complex amalgamation of the familiar and strange. They were invented, idealized spaces long before being "discovered". The arctic is in many ways the contemporary stage for imaginary exploration, reprising the role it played at the turn of the $20^{\text {th }}$ century during which Western audiences flocked to witness moving and still images of the first men to reach its pole. Today the image of the melting polar icecap is possibly the most recognizable feature of popular iconography surrounding the climate change debate. While the arctic functions as a real place for Kunuk, for a large portion of the population in the West it exists solely as an imagined space which can only be experienced through its representation.

Sirmilik opens with a series of shots which attempt to capture as much of the space as possible. The camera slowly moves right, tracks forward along the vertical, then shifts towards the left and finally tilts back down from the cloudy sky to the series of mountains down below. The first three shots moving to the right are taken far above the land. These aerial shots (as shown in Figure 1), which are composed at an oblique angle emphasizing the vast dimensions of space without flattening the topography, move around in a circle, finally ending at ground level looking out towards a sublimely composed mountainscape.

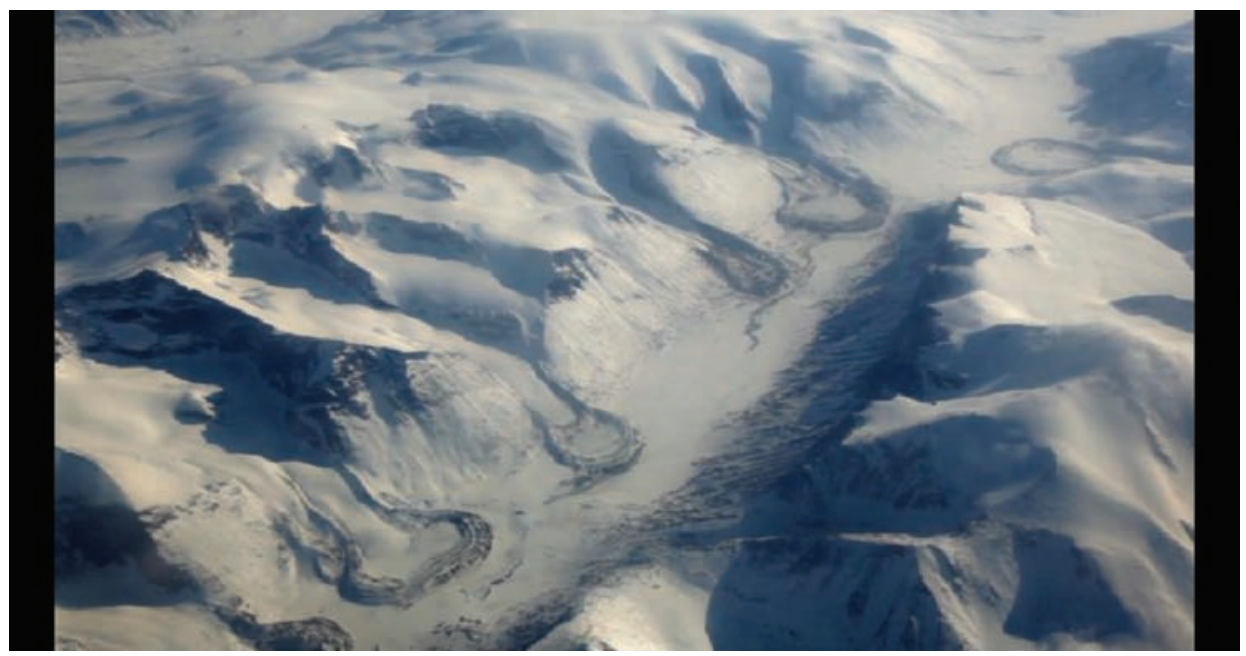

Figure 1. Aerial imagery which displays the vast dimensions of space without flattening the topography

While Sirmilik opens with a series of aerial panoramas, it quickly closes in towards the Pond Inlet which remains just below the mountains. First a series of cuts leads us from the frozen Eclipse Sound to a long shot depicting a series snowmobiles being packed with supplies. The voice over begins in Inuktitut: "At the age of five every morning I was awaken by my father, who used to tell me to 
go out early. So in the future I will be a hunter. When I went out I would look up at the sky. Not concerned about anything, whether it was windy or cloudy, I was just looking." The camera takes us across the water from the back of one of the snowmobiles.

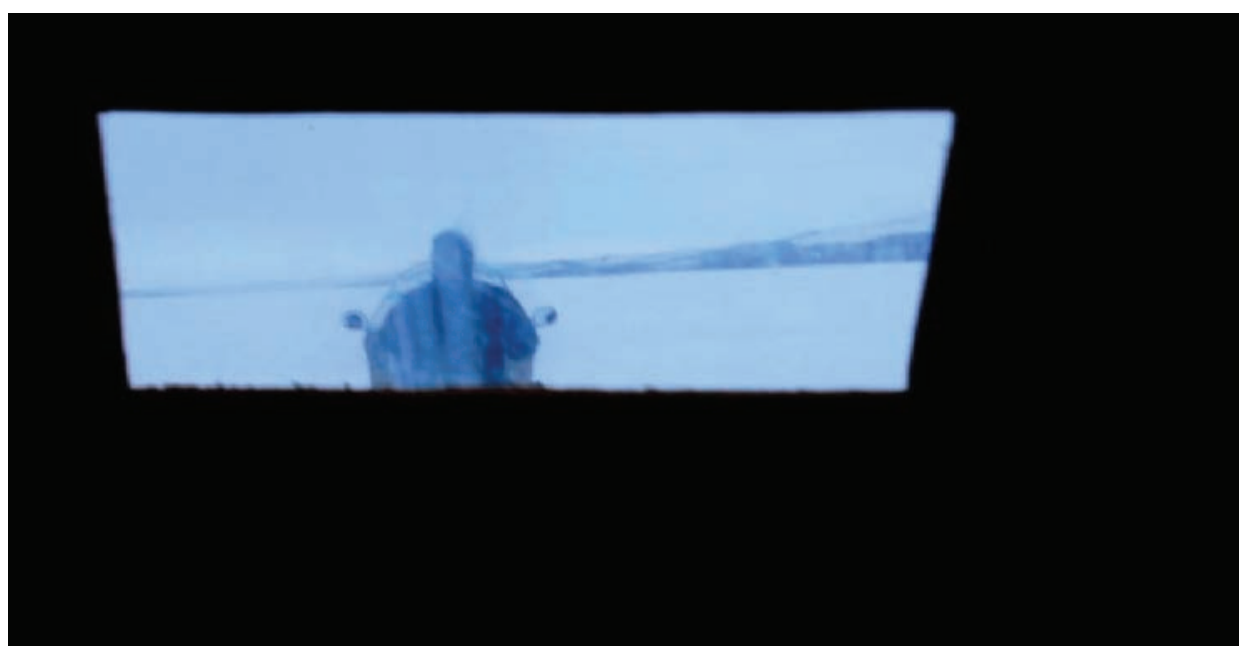

Figure 2. The camera takes us across the water from the back of one of the snowmobiles

Before the Inlet comes into sight a slow panning shot surveys the mountain range surrounding the area on all sides. The inlet is revealed slowly, first with a long line of mobile buildings, then the side of the community's co-op building and finally with a group of children playing together on a makeshift basketball court. "I grew up by my father's side, he taught me all things I should know about hunting and igloo making he was the one to teach me how to catch animals the easiest way. It has come to this day and I still follow my father's teachings when I'm hunting." In a new shot the children run amongst a set of water pipes and rusting construction material. The dark browns and reds sit dramatically against the bright white plateau and mountain range lining the background. Shots of water appear, sliding down the inside of the pipe, slowly blowing across a pond and dripping down an icicle, all intercut with images of the glaciers. Time seems to be slipping forward, Kunuk uses time lapse photography to reproduce the clouds rushing by still mountains. "When the sky is cloudy and the clouds are round my father said to study it. And when the sky is clear and round clouds appear he would tell me that it's going to be windy by the evening." Soon atmospheric changes mask the presence of the mountains which were so clear before. Storm clouds begin to rush in and the snow recedes. A tracking shot reveals the elderly man who soon is associated with the voice over. He is riding a snowmobile but is garbed in traditional clothes. The camera finds the man again at the base of 
a mountain as he cuts a whole in the frozen ground. Between a series of landscape images, the man is portrayed skinning a seal. This montage dissolves into a close-up of a set of letters and numbers carved into a reddish brown rock face. The image turns into another close-up of words and symbols, this occurs again and again as the camera set ups move farther away from the dry rock formations. Again the older man appears, back amongst the snow and ice. In Figure 3 we see him leaning up against a wooden shed while looking up at the sky, "These days the weather seems to have changed. I seem to make a mistake when I try to predict the weather."

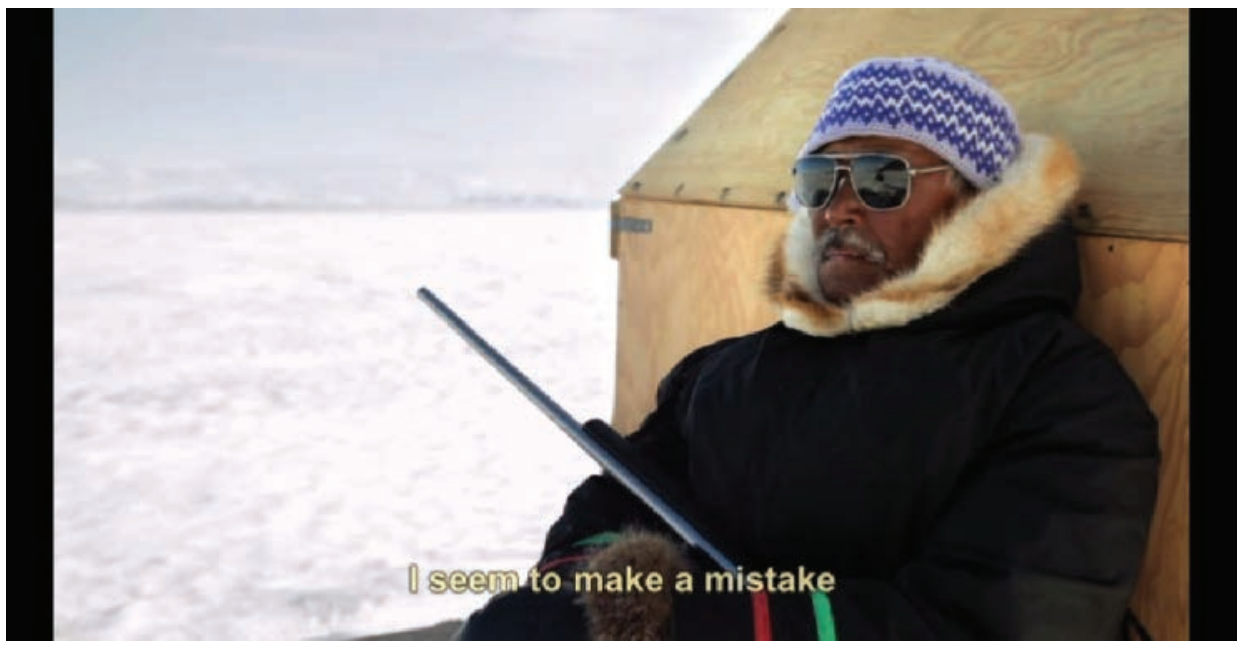

Figure 3. "I seem to make a mistake..."

The last shot presents a faraway mountain which is startlingly composed of black rock and white snow peaks creating a dramatic juxtaposition of light and dark (as shown in Figure 4). Another set of dark clouds creep in as the screen fades to black.

The film creates a rhythmic pattern of immersion and detachment, playing with levels of access for the viewer. The first series of sequences reflect the traditional approach to framing and constructing natural spaces. Both the moving aerial and static landscape images utilize their different levels of distance from the land to present the illusion of an omnipresent observer. Their shared cultural history privileged distance over participation in addressing and developing stable representations of space. Both artistic practices developed out of other domains and were embedded in larger theoretical and cultural lineages born out of linear perspective.

Cultural geographer Denis Cosgrove wrote extensively on the relationship between the visual representations used by geographers and those created by artists. 


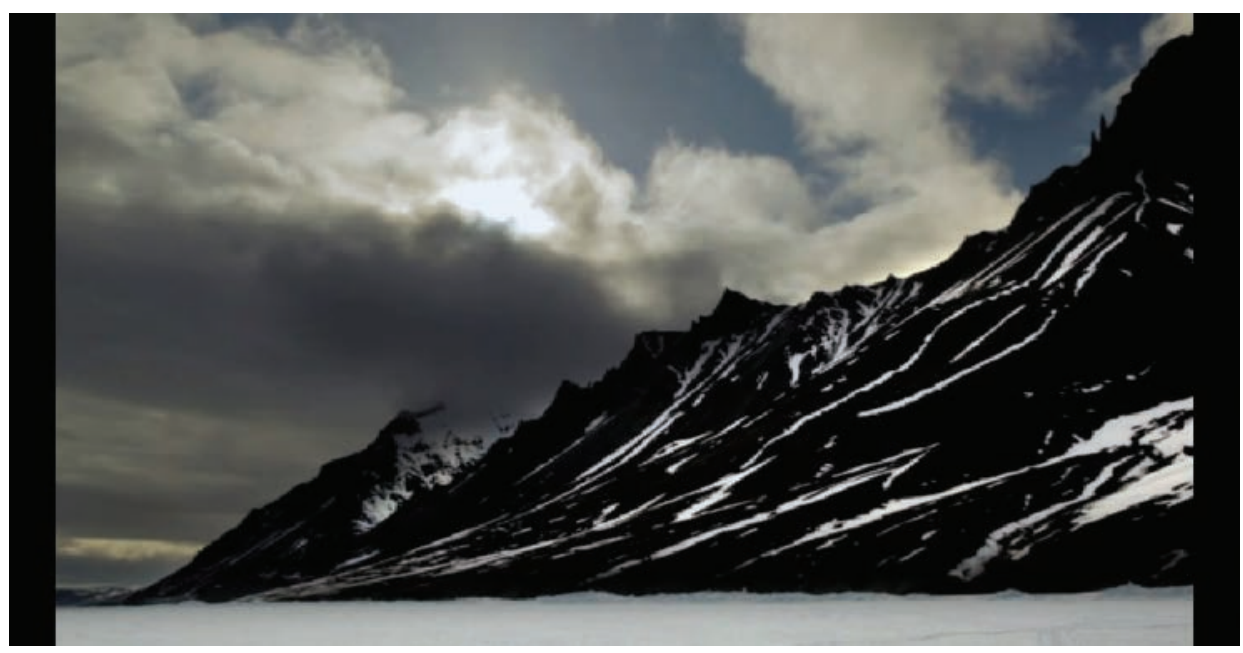

Figure 4. A dramatic juxtaposition of light and dark...

He noted that landscape painting was able to do ideologically and visually what survey techniques did practically, that is to create the illusion of a total domination over space (1985: 46). This was possible because both disciplines employed the same technique developed in Euclidean geometry: linear perspective. Its employment acted as a "guarantor of certainty in spatial conception, organization and representation" (Cosgrove 1985: 46). Linear perspective guaranteed the sovereignty of the eye in both the practical sciences and fine arts, privileging the individual's gaze over all else. It allowed for the representation of three dimensional space "through single-point perspective theory", creating the possibility for greater realism by determining the dimensions and distances of specific forms and structures from the relative position of the viewer (Cosgrove 1985: 47). Even as the rules governing linear perspective were debated over the centuries there were always new forms of geometric continuity to take its place.

Within the fine arts linear perspective allowed artists not only to create realistic representations of three dimensional landscapes but also to control the way each viewer engaged with their paintings. The artist was able to determine the point of view of the observer; he directed "the external world toward the individual located outside that space" (Cosgrove 1985: 48). Space became the property of the detached observer who was able to enter the image visually along the perspective axis and move through the landscape, finally exiting at the vanishing point. Distance in this case determines mastery for the artist and the viewer as both engage in similar forms of passive observation, further widening the subject/object divide. This in fact is the most consistent role of landscape art throughout history: to present order, control and unambiguous meaning in the face of overwhelming tension and conflict between nations, social groups and the environment. While 
conventional ideas of landscape and perspective were challenged in the Romantic period, the underlying epistemological assumptions privileging the individual and the gaze remained in the European and North American popular imagination (Cosgrove 1985: 58).

This mastery of space is replicated in the aerial photograph. Like landscape paintings reliance on perspective, aerial photography (and film) appropriates space through its reliance on technology. The apparatus employed explicitly drew on the same formula of perception and realism; the camera lens became the "culminating realization" of linear perspective, embedding this form of seeing into every reproduced image (Heath 1981: 30). The camera was arguably even better at disguising and naturalizing those techniques and epistemological assumptions which it retained from geography than geography itself, all of which constructed an image of space as accessible and stable.

Landscape techniques employed in cinema borrow heavily from both aesthetic (stylistic conventions of the sublime or picturesque and formal conventions such as the popular $19^{\text {th }}$ century panorama) and geographical traditions. All of these techniques are associated with a conception of scale, whether it be related to the one introduced by cartography or by other forms of spatial representation. Historically, geographers privileged the map and regarded it "as the origin of geographic questions and the most appropriate expression of their answers" (Cosgrove 2008: 4). The calculation of scale had the same effect as linear perspective, it portrayed itself as more than a mere representation of space; it replicated areas in an "objective" manner that could supply empirical evidence about the world to both scientists and the layman. Outside of cartography, scale often exists embedded in perspective as a deceptively simple heuristic device. In landscape painting and photography the heuristic allows for a spectator to immediately orient themselves within a represented space and compare it with their perceptual experience of reality. Christopher Lukinbeal has recently argued that scale as a form of representational practice is schizophrenic in nature: "Scale is a representative and expressive analogy that compares things based on similarity while hiding their difference. As an analogy, scale seeks to provide spatial structure for the purpose of clarification and explanation; however, it only works by concealing its alterity, its schizophrenia" (2011: 2). In other words the practice conceals the conceptual discourse which precedes the representation through a "scalar re-presentation of reality with no subjectivity," something Luckinbeal refers to as the "mimetic dream" (3). These conventional patterns attempt to mimic how the universal subject would encounter and move through the real world thereby convincing its audience of the absolute realism reproduced on screen (Lukinbeal 2011: 4).

In both the aesthetic and geographic domain, scale replicates a singular and universal mode of spatial awareness which remains the basis of traditional geographical knowledge and scientific objectivity. Topographic aerial views merge the two domains without offering the viewer any comparative visual information which would allow them to determine scale. The viewer must infer the stability of their omniscient position based on the network of cultural meaning that these 
forms of views are embedded within. Aerial images rely on their juxtaposition within the film and assumptions already held by the viewer about their indexical relationship to their referent in order to construct a stable representation of space. In this sense mastery over the landscape remains precarious, and is necessarily dependent on exposure to other references to scale.

While Zacharias Kunuk had rarely employed aerial shots prior to the making of Sirmilik, he has used different maps in his documentaries in order to emphasize specific locations and their relationship to the rest of Canada. The use of maps is significant because it reflects the political importance of specific places for Kunuk and other Inuit. This conceptual re-appropriation of land is demonstrated by establishing boundaries and contextualizing significant locations. Both groups use these forms of representations to establish relationships with space, though in profoundly different ways; the European colonial used aerial perspectives and landscape images to order and control unknown spaces while the aboriginal communities used them to understand their own environments and, more recently, to take a stand against years of cultural, political and economic domination.

The creation and existence of the national park system in North America attempts to preserve the ideals and divisions associated with the same forms of stability and control that are employed by aerial imaging. Its dual function replicates the nostalgia often associated with landscapes, one that wishes to escape the present complexities and failures of imperialism and late capitalism. Mitchell describes the relationship as follows:

Landscape is now more precious than ever - an endangered species that has to be protected from and by civilization, kept safe in museums, parks, and shrinking 'wilderness areas.' Like imperialism itself, landscape is an object of nostalgia in a postcolonial and postmodern era, reflecting a time when metropolitan cultures could imagine their destiny in an unbounded 'prospect' of endless appropriation and conquest. (Mitchell 2002: 20)

The national park preserves the division between nature and culture while at the same time thoroughly domesticating the "nature" that is constructed within. These pieces of nature come to be emblems of national identity, an inexhaustible commodity drawing local and international tourists to bask in relaxation and sporting activities inside its boundaries. In these cases culture grants nature the right to exist, just like the nation grants the aboriginal their continued existence, albeit in a tamed and contained form.

Much of the centennial campaign orchestrated by the government of Canada reaffirms these aspects of the National Park network. Many of the films depict stunning vistas, idyllic settings and individuals traveling through in order to enjoy them. Sirmilik, the park and film, located inside Nunavut, is by contrast, contested space. The national park sits on the north side of the Pond Inlet and is surrounded by a patchwork of Inuit owned land and Crown land. It is made up of three pieces of land in the Arctic Archipelago separated by a natural waterway and includes the 
Bylot Island, a migratory bird sanctuary. The glaciers depicted on film all face the Inuit community living along the edge of the Inlet. The community and area has had a long history of contact with outsiders. In 1912, a year after the establishment of the first Canadian national park, the first trading posts were established by explorers looking for gold in the area. While the inlet has been a traditional site for hunting and fishing for 4000 years, it was not until the federal government required Inuit children to attend school in the early 1960's, and built residential schools in the area, that families eventually moved into the built settlements (Parks Canada). The very existence of buildings is testament to this terrible history. Kunuk does not shy away from the complexities of representing this national park from the point of view of the Inuit. The national parks project is on a whole celebratory, but Kunuk's film is not. Layered on top of the series of landscape images is a dire warning about the result of years of changes enacted by outsiders and the consequences for the Inuit living in the North. This warning cut's directly into the assumptions we hold about knowledge and experience of land and space, whether it be local or about places half way across the globe.

How we experience the space around us in our everyday lives differs significantly from how we understand it inside scientific practices. Geographer Edward Relph suggests that our assumptions about space revolve in-between two distinct modes of being: the scientific and prescientific or phenomenological. The prescientific offers us our immediate sensory contact with our environment. Often the scientific overwhelms our immediate experience and the prescientific becomes obscured by structures of abstraction (Relph 2000: 16). In Being and Time, Heidegger describes these two forms of being-in-the-world as presence-at-hand and readiness-to-hand. They form a complementary tension that accounts for the complexity of our understanding of landscape.

Readiness-to-hand refers to our direct immediate relationship with the objects in the world. Use and its value is its "primordial form" and it encompasses a huge variety of activities (Relph 2000: 18). This form of being inserts us directly into a network of meaning attached and related to inhabitation and action. The network allows us to use and interact with the objects around us and differentiates between these objects and the spatial surroundings or background which cannot be used (Relph 2000: 19). Each task's completion is dependent on our awareness of a certain spatial relationship and context connecting, for example, a table, pencil and paper to the act of writing (Relph 2000: 18). As we use different objects as equipment and move through space our network becomes more complex. Each person is constantly navigating their way through this network of classification. But this navigation is immediate, it is an extension of our ontology as beings who are "always and already in a world which they are concerned" (Relph 2000: 18). It is the lived geographical meaning which allows us to interact with each other and the world.

In contrast presence-at-hand enacts a certain self-conscious separation from the world around us (Relph 2000: 17-18). This distance allows for observation and contemplation affording us the opportunity to think about the world around 
us. It comes about in numerous situations when reflection and abstraction is necessary. Presence-at-hand is not a form of objectivity or guarantor of truth but a different mode of involvement and proximity with the world inside existence (Relph 2000: 19). It does offer the opportunity to develop answers to foundational questions in philosophy and the sciences by allowing for "an element of self-awareness [to] insert itself" between the world and the individual (Relph 2000: 18). Relph argues that the danger comes when it is co-opted by academia and privileged over readiness-to-hand in order to ascertain truths about the world. Neither modes of existence can occur without the other as will be discussed with relationship to landscape and place.

My previous discussion of traditional landscape aesthetics firmly placed them in the realm of presence-at-hand. For academic geography, landscapes are visual texts which have to be approached "with a measured and detached gaze of curiosity and with skepticism about why things look as they do" (Relph 2000: 18). But during everyday experiences the landscape idea is far more complicated. It relies on a context of experience and extends from specific physical and psychological places. The term landscape exists in an intermediate stage; it is both an immediate experience and something constantly out of reach. Eric Dardel wrote that "a landscape is something more than a juxtaposition of picturesque details; it is an assemblage, a convergence, a lived-moment," (in Relph 2000: 23) one that is united by a certain period of time, a certain concern and a certain physical state that shifts and moves alongside the person experiencing it. The place where we experience a landscape from is qualitatively different. Places are constructed through repeated encounters and are qualified by memory (Relph 2000: 26). Places are origin points and for Heidegger represent the context for things ready-to-hand. Neither landscapes nor places are the sum total of objects which they encompass. In Being and Time Heidegger states; "when space is discovered by just looking at it, [it is] neutralised to pure dimensions. Places - and indeed the whole circumspectively oriented totality of places belonging to equipment ready-to-hand - get reduced to a multiplicity of positions for random Things" (in Relph 2000: 27). These objects only have meaning inside an embodied experience. This experience activates the conceptual network. The division between place and landscape is constantly shifting and blurring. Landscape emerges out of the background of ready-to-hand through a shift of perception, it emerges out of place. These backgrounds, which usually go unnoticed as contexts for daily life, take on new symbolic meaning.

Certain places (and space in general) have a fundamental role in defining and creating limits on the knowledge. Heidegger pinpoints dwelling as the fundamental characteristic of being on the earth. Dwelling is so habitual that we are often oblivious to its importance. Dwelling encompasses all other activities that take place. Heidegger writes, "to say that mortals are is to say that in dwelling they persist through spaces by virtue of their stay among things and locations" (1993: 359). By persisting through spaces he means constructing and preserving a certain equilibrium between the world and other beings. This world is always present 
before we are, we discover ourselves through our placement in that world. "When we speak of man and space, it sounds as though man stood on one side, space on the other. Yet space is not something that faces man. It is neither an external object nor an inner experience" (Heidegger 1993: 358) Heidegger equates thinking with building subsumed under the principles of dwelling. In his essay "Building, Dwelling, Thinking," Heidegger uses the example of a bridge as metaphor for both concepts. Bridges create admittance into spaces; they turn "space" into specific places of dwelling. Thoughts or mental pictures do the same thing; they transport us to the location of our experience. Each thought breaks down spatial distance:

If all of us now think, from where we are right here, of the old bridge in Heidelberg, this thinking toward that location is not a mere experience inside the persons present here; rather, it belongs to the nature of our thinking of that bridge that in itself thinking gets through, persists through, the distance to that location. From this spot right here, we are there at the bridge-we are by no means at some representational content in our consciousness. (1993: 358)

Even when considering an object or question through a detached, present-at- hand form of contemplation, an individual must navigate through experiences bound to space. Thoughts are never, ontologically speaking, completely detached; while they "persist through" space, they do not rise above it or overcome it like an aerial view. Rather they allow us to think about other places that we have experienced while still remaining physically where we are. They allow us to focus our attention on certain aspects that previously remained in the background. Distance and closeness are therefore constructions bound to the tension between present-athand and readiness-to-hand.

Tim Ingold incorporated Heidegger's concept of dwelling when reconsidering landscape. He challenges the concept which I explored at the outset of this paper through privileging the temporality of space which he calls the "taskscape". He approaches landscapes through the ensemble of tasks where individuals (whether they are humans or other animals) interact with others. Traditional landscape representations (painting, photographs etc.) perform a role completely unlike the original natural experience. These landscape experiences exist at a particular "relational" nexus that cannot be "cut" directly out from the whole (Ingold 1993: 155). Rather than existing in an immobile state like a painting, landscapes are changing constantly both physically and symbolically, even though many of those changes are not immediately perceptible. Ingold argues for an emphasis on process rather than inscription in his own discipline of anthropology. Process values an open ended integration of agents and landscapes, one that is constantly under construction from both sides, while the term inscription suggests that the rest of the world remains still while agents leave their own imprint upon it (Ingold 1993: 157). This is of course the illusion created and sustained by traditional aesthetics of distance; nature stands on one side and 
humans on the other with landscape performing the role of stand-in, mediating any fears that we are not in control.

Film is the perfect medium to consider the tension inherent in the experience of landscape and perhaps the easiest way to construct and rupture illusions of stability. Not only does film temporalize space, creating a representation of space that is closer to everyday experience, but it also expands on the complex relationship that personal and cultural narratives have with landscapes. Martin Lefebvre has recently argued that film is never able to become a vehicle of detached contemplation like a still image could. By borrowing from geography and anthropology Lefebvre was able to resolve some of the tensions inherent to traditional definitions of landscape aesthetics and film. Moving images are always negotiating both the temporal and spatial, and, therefore, display images that resist being held and contemplated for long periods of time. Film always attempts to draw us in, to be immersive, because it is never purely visual; these landscapes exist in a certain temporality necessarily enhanced by camera movement, diegetic sound and music (Lefebvre 2011: 74). Those forms of landscape that Lefebvre refers to through the aesthetic tradition, namely intentional or impure landscapes, where the image momentarily breaks from the narrative, always remain deeply implicated (or "haunted") by the characters and profilmic world (Lefebvre 2011: 70). Narrative no longer remains in opposition when considered through "taskscapes", it becomes the temporal representation of human dwelling and can "function as a key element in the experience of landscape as live space in film" (Lefebvre 2011: 74). Narrative can both reveal and conceal different complexities inherent in the way we consider the concept of landscape.

Sirmilik reverses the role of landscape and narrative, constructing its warning about the effects of climate change through images of the natural. Kunuk uses the juxtaposition of different formal examples of landscape to present the fundamental distinction between the geographical knowledge created by the Canadian Inuit and that mandated by North American and European academia. Landscape, as has been discussed, is a formal construction bound to complex epistemological assumptions. Borrowing from Catherine Russell's methodological vocabulary, Kunuk "allegorizes" landscape by referring directly to the image or representation of nature, rather than nature itself, in order to demonstrate how the original experience is itself a constructed entity. Kunuk plays with its construction turning it into his own cultural production bringing the landscape closer (Russell 2006: 163). "Once the landscape is an artefact, we are better able to recognize ourselves - the human - in its construction" (Russell 2006: 149).

Kunuk plays with motion, proximity and distance by incorporating three different levels of formal staging alongside repetitive editing patterns. These replicate assumptions about spatial coherence and stability. The film's images exist on a sliding scale; moving from still, contemplative landscape images to, at the other end of the spectrum, tracking shots following moving bodies across the land. As mentioned earlier, the majority of shots are organized around conventional landscape aesthetics. They are shot at some distance from their object of interest 
(usually a glacier or mountain range) without any form of camera movement. These static shots are almost identical to photographs; the scene remains perfectly still for the viewer with the only exception being a lone bird flying in the background of a few of the images. Motion begins to slowly emerge out of these series of shots. The camera breaks down and out of its contemplative perch and tracks forward, penetrating space. One of the first examples of this technique occurs early on, after a long, slow aerial pan, allowing the eye to grasp at every edge of space, the camera plunges forward, moving quickly along the frozen plateau towards the mountains. This shot is abruptly ended by a cut to another slow pan which is again situated amongst the clouds. While short lived at the beginning of the film, this form of hybrid aesthetic where the gaze of the viewer is reattached to the motion of body, marks a shift in the privileging of the gaze over the body in the breakdown of distance, leading toward the opposite emphasis, where the camera closely tracks individual people moving around in space.

Editing patterns play with the same problematization of bodies and space. Kunuk does not immediately move from landscape images to individuals but instead closes in on them through exterior signs of their existence, like buildings and snowmobiles. He does this in patterns of three: three separate shots of the same location or image which either moves us consecutively closer or farther away from the object at the centre. This first occurs in the seventh shot of the film with the image of the snowmobiles and sleds being packed for the journey over the frozen water (as shown in Figure 5). Each image of this series of shots jump's farther and farther back from the original until an extreme long shot reveals the set of mountains in the background. This pattern is repeated again, directly after, as the camera position jumps from behind a man driving a snowmobile to another extreme long shot of the snowmobile running along the plateau. Later in the film when we finally arrive at the Inlet, the reverse series of shots occurs as the camera moves closer and closer to the buildings. Sirmilik is always shifting in and out of locations and perspectives. Rather than creating a formal linear chain alongside the narrative, it plays in subtle ways with the unexpected. It juxtaposes detail from different levels of proximity creating an assemblage that conceals and reveals the problem of landscape.

These ambiguities are brought to the surface through the voice of the elder accompanying the film. In it the man refers repeatedly to the relationship between looking and predicting changes in the weather and the environment. He also creates a parallel between looking and traditional forms of Inuit knowledge that are performed while traveling and hunting on the land. But while the voice over emphasizes looking up at the sky, the images which it is layered on top of are shots of people in motion. These people perform everyday activities, hunting, playing and building without directly contemplating the scenery around them. It is not until the second last shot of the film that the voice and image are reconciled. Here the elderly man finally pauses and looks up at the darkening sky while he laments the fact that he can no longer predict the weather. The film seems to break into two replicating the mind/body dichotomy; the landscape images emphasize the 

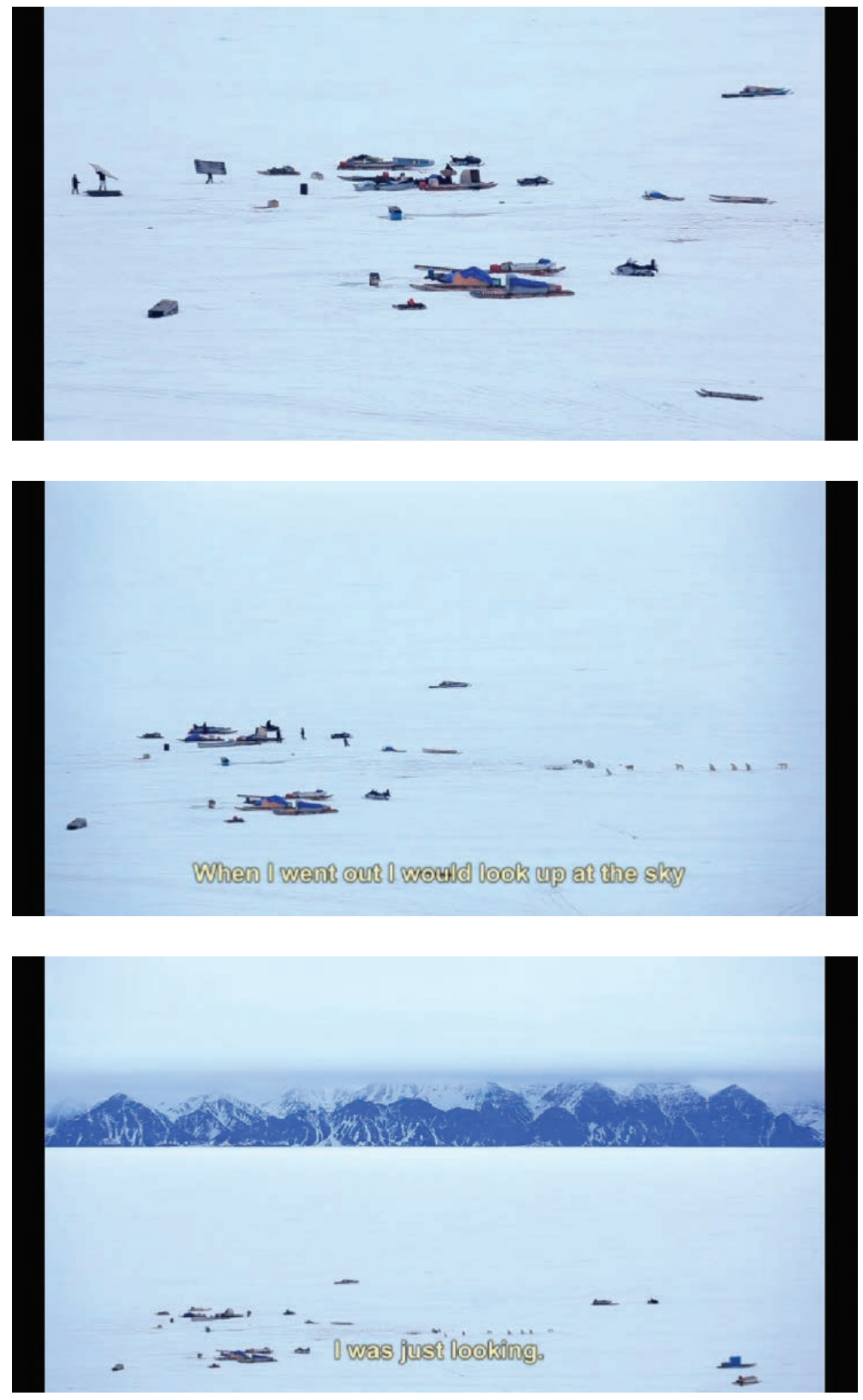

Figure 5. Patterns of three... 
detached contemplation of the audience while the other images represent the lives of the community who lives in the Inlet; we look and they move.

Inuit have a fundamentally different way of creating knowledge out of their experience with the land, one that mirrors the tension between presence-at-hand and readiness-to-hand. The contemplative act is situated inside the structure of embodied experience, one that at a prior time proved to be accurate. This hybrid contemplative space is made up of a dynamic interplay of immersion and detachment. The elder in the film constructs knowledge through a direct causal relationship with specific places which have been part of a shared symbolic oral history. This knowledge interacts, reacts and accumulates through the natural objects and tools around him but is also self-reflexive about these same structures of interaction. Detachment in this case is only useful in constructing ideas about places close to home, places that have first been physically navigated through. Here the two forms of knowledge are contrasted, condemning the changes and assumptions which have occurred elsewhere. The aerial views which assert a disembodied dominance over space eventually become replaced by images looking at the landscape from the ground. Both exhibit a form of detachment in order to perform as material of contemplation, but only the latter is aware of its physical relationship to the space and the limitations constructed based on that position.

The arctic acting as battle ground for the climate change debate is nothing new, but in this film Kunuk takes the debate to the level of representation and geographic knowledge. Traditionally landscapes became synonymous with nature, emphasizing a one sided relationship where the environment becomes a series of tabula rasas waiting to be completed. In these cases the farther away we are from the space the more control we believe we have. This dramatic form of distance, and the circulation of representations recreating this detachment, shaped the illusion that one form of knowledge could completely replace every other. Epistemological certainty in this case relates directly to a disassociation from the fallibility of the body and the senses, an overcoming of our limits of understanding which remains the bedrock of the practical sciences. In Sirmilik the audience both observes the landscape with the Inuit and observes the Inuit in the landscape. We become complicit as detached observers forced to ask what we really know about the arctic just by looking at it.

Landscape, like its history, appears deceptively simple. Judgments about natural landscapes and their representations have been conventionally governed by the formal aesthetic domain. Multiple different sets of structures operate alongside these judgments which, in natural settings, shift ubiquitous backgrounds which have been trampled through again and again to sublime landscapes considered from a distance. This change in emphasis occurs for numerous reasons owing to larger cultural, political and philosophical issues. Every day experiences with the environment, natural and built, are often overlooked in geography, and yet they have a fundamental effect on every other form of knowledge production. The term landscape exists at the nexus of immersion and detachment. Our ability to interpret it relies on and is limited by the dichotomy. Its qualitative, relational 
nature makes it highly resistant to understanding. Somewhere inside the tension lies the most interesting and revealing conception of the landscape idea.

\section{References}

Cosgrove, Denis E. (1985) "Prospect, Perspective and the Evolution of the Landscape Idea". Transactions of the Institute of British Geographers 10 (1), 45-62.

Cosgrove, Denis E. (2008) Geography and Vision: Seeing, Imagining and Representing the World. London: I.B. Tauris.

Heath, Stephen (1981) Questions of Cinema. Bloomington: Indiana UP.

Heidegger, Martin (1993) "Building, Dwelling, Thinking". In: Farrell, David (ed.) Basic Writings. New York: Harper Collins, 343-363.

Heidegger, Martin (1996) Being and Time. Albany: State University of New York.

Ingold, Tim (1993) "The temporality of the landscape". World Archaeology 25 (2), 152-174.

Lefebvre, Martin (2011) "On Landscape in Narrative Film". Canadian Journal of Film Studies 20 (1), 61-78.

Lukinbeal, Christopher (2011) “Scale: An Unstable Representational Analogy”. Media Fields Journal 4, 1-13.

Mitchell, W.J. Thomas (2002) “Imperial Landscape”. In: Mitchell, W.J. Thomas (ed.) Landscape and Power. Chicago: University of Chicago, 5-34.

Relph, Edward (2000) "Geographical Experiences and Being-in-the-World: The Phenomenological Origins of Geography". In: Seamon, David and Robert Mugerauer (eds.) Dwelling, Place, and Environment: Towards a Phenomenology of Person and World, $2^{\text {nd }}$ ed. Malabar, Florida: Krieger, $15-32$.

Russell, Catherine (2006) "The Inhabited View: Landscape in the Films of David Rimmer". In: Lefebvre, Martin (ed.) Landscape and Film. New York: Routledge, 149-166.

"Sirmilik National Park of Canada". (2009) Parks Canada. Government of Canada. http://www. pc.gc.ca/pn-np/nu/sirmilik/natcul/natcul4.aspx, accessed on 10 March 2012.

\section{Filmography}

Atanarjuat: The Fast Runner. Dir. Zacharias Kunuk. 2001.

The Journal of Knud Rasmussen. Dir. Norman Cohn and Zacharias Kunuk. 2006.

Before Tomorrow. Dir. Marie-Helene Cousineau and Madeline Ivalu. 2008.

Sirmilik. Dir. Zacharias Kunuk. 2011.

Samantha WiLson is a PhD candidate in the Film and Moving Image Studies program at Concordia University. She previously completed a MLitt at the University of St. Andrews in Philosophy and is currently researching the formal depiction of natural landscapes in $19^{\text {th }}$ century painted panoramas, topographical literature and early British cinema through the lens of the $18^{\text {th }}$ century Sublime. Her other research interests include: environmental ethics; Indigenous media; film and photographic technology; and, classical film theory.

Address: Samantha Wilson, Mel Hoppenheim School of Cinema, Faculty of Fine Arts, Concordia University, Canada. [email: samantha.wilson@concordia.ca] 
